than one in 3300 (cimetidine), one in 2300 (labetalol), and one in 3900 (benoxaprofen) cases were likely to have been observed. Because of incomplete follow up of patients receiving labetalol and benoxaprofen, the final tally was about one in 1400 and one in 1900 respectively. This probably explains the failure to detect a significant increase in adverse reactions on the liver associated with benoxaprofen or the lichenoid skin eruptions with labetalol. Indeed, in his Wolfson lecture at Oxford in January 1984, Inman presented preliminary results from a larger $(24000)$ cohort of patients receiving benoxaprofen: of the 54 patients who developed jaundice while taking the drug, there was one (non-fatal) case where treatment could be blamed and a further 11 cases (including six with incomplete follow up) when alternative causes could not be entirely ruled out. Even so, this may underestimate the problem since the duration of treatment with benoxaprofen in Inman's most recent study averaged about seven months while the average duration of treatment in patients with fatal hepatorenal syndrome associated with benoxaprofen reported to the Committee on the Safety of Medicines was 8.5 months. ${ }^{16}$ Increasing the number of patients in postmarketing surveillance studies, as well as including sufficient numbers undergoing prolonged treatment, would enhance the sensitivity of the technique but substantially increase the cost.

The need for controls in postmarketing surveillance studies seems to me to be clear. This is particularly the case when adverse "events" are to be recorded, when the underlying disorder is itself associated with substantial morbidity or mortality (for example, hypertension), or when it is likely that the drug will increase the incidence of commonly occurring symptoms or diseases (for example, impotence or diabetes mellitus). Thus, in the recent ketotifen study, the significance of adverse "events" occurring during follow up (including weight gain and non-fatal myocardial infarction) is impossible to evaluate. Yet the choice of a control population is difficult. The ideal group-patients suffering from the same disease but undergoing no active treatment-is unattainable for long term studies except in very special circumstances. More realistic controls include patients treated with a comparable drug (as in the benoxaprofen study) or a sample of the general population (as in the cimetidine study).

For the future we need to be able to identify the drugs to which these postmarketing surveillance techniques might most profitably be applied. In general, the balance between risk and benefit most needs to be examined with drugs for disorders which are not life threatening and when reasonably safe alternatives are already available. Such studies are likely to be worth while, however, only if they enrol at least 10 times the number of patients in the premarketing trials and include a reasonable comparative control group. They will therefore need to include at least 10000 patients and 10000 controls, and the cost will be substantial. Yet they will detect, with $95 \%$ confidence, only those events occurring in one in 3000 patients. For many drugs, and for the recognition and confirmation of less common reactions, we must therefore continue to rely on published anecdotal reports, the yellow card system, case-control studies, and examination of mortality and morbidity statistics.

Michael D RaWlins

Professor of Clinical Pharmacology, Wolfson Unit of Clinical Pharmacology, The University,

Newcastle upon Tyne NE1 7RU
1 Venning GR. Identification of adverse reactions to new drugs. III: Alerting processes and early warning systems. $\mathrm{Br}$ Med $\mathcal{F} 1983 ; 286$ : 458-60.

${ }^{2}$ Inman WHW. Monitoring for drug safety: the United Kingdom. In: Inman WHW, ed. Monitoring for drug safety. Lancaster: MTP Press Ltd, 1980:9-47.

${ }^{3}$ Stolley PD. The use of vital and morbidity statistics for the detection of adverse drug reactions and for monitoring of drug safety. $\mathcal{F}$ Clin Pharmacol $1982 ; 22: 499-504$.

4 Mann JI. Principles and pitfalls in drug epidemiology. In : Inman WHW, ed. Monitoring for drug safety. Lancaster: MTP Press Ltd, 1980: 401-15.

5 Royal College of General Practitioners. Oral contraceptives and health. Tunbridge Wells: Pitman Medical, 1974.

${ }^{6}$ Dollery CT, Rawlins MD. Monitoring adverse reactions to drugs. $\mathrm{Br}$ Med 7 1977; :96-7.

7 Inman WHW. Recorded release. In: Gross FH, Inman WHW, eds. Drug monitoring. New York: Academic Press, 1977:65-78.

${ }^{8}$ Lawson DH, Henry DA. Monitoring adverse reactions to new drugs "restricted release" or "monitored release" ? $\mathrm{Br} M e d$ F 1977;i:691-2.

Wilson AB. Postmarketing surveillance of adverse reactions to new medicines. Br Med F 1977; ii:1001-3.

10 Colin-Jones DG, Langman MJS, Lawson DH, Vessey MP. Postmarketing surveillance of the safety of cimetidine: 12 month mortality report. Br Med F 1983;286:1713-6.

11 Glaxo Group Research Registration Department. Monitored release of Trandate in general practice. London: Glaxo Group Research, 1980.

12 Inman WHW. Prescription-event monitoring. A preliminary study of benoxaprofen and fenbufen. Southampton: Drug Surveillance Research Unit, University of Southampton, 1982.

13 Inman WHW. Brand names, approved names, and drug safety. Lancet $1982 ; \mathrm{i}: 1078$.

14 Inman WHW, Rawson NSB. Erythromycin estolate and jaundice. $\mathrm{Br}$ Med F 1983;286:1954-5.

${ }^{15}$ Sackett DL, Haynes RB, Gent M, Taylor DW. Compliance. In: Inman WHW, ed. Monitoring for drug safety. Lancaster: MTP Press Ltd, 1980:427-38.

${ }^{16}$ Griffin JP. The advantages and limitations of drug orientated schemes for monitoring adverse drug reactions. In: Walker S, Goldberg A, eds. Monitoring for adverse drug reactions. Lancaster: MTP Press (in press).

\section{Hypertension in general practice: what is to be done?}

Two publications from the Veterans Administration Cooperative Study Group on Antihypertensive Agents in 1967 and 1970 and the subsequent trial by the National Heart Foundation of Australia provided the evidence that substantial numbers of asymptomatic patients would benefit from reduction of their blood pressure. ${ }^{1-2 a}$ The potential beneficiaries are those with sustained diastolic pressures above $100 \mathrm{~mm} \mathrm{Hg}$ (phase V), who make up at least $7 \%$ of the population between 35 and 65 years old-which in Britain means over a million people. This takes no account of the much larger numbers with diastolic pressures between 90 and $100 \mathrm{~mm} \mathrm{Hg}$ or of the hypertensive elderly, but both these groups are at present the subject of clinical trials.

The formidable problem of identifying and treating a million or more patients was neatly described over a decade ago in the rule of halves. Surveys had shown that in an unscreened population half the hypertensive patients would not have been identified, of those identified only half would have been having treatment, and of those treated half would have been treated inadequately. This rule set a target for education of general practitioners and trainees, who have been repeatedly encouraged to look for hypertensive patients and institute and maintain treatment. Hart showed what could be done in an individual practice as long ago as $1970,{ }^{3}$ and further publications have spelt out the elements of an effective and practicable policy. ${ }^{5}$ The Royal College of General Practitioners, too, has decided that the main direction of growth for the primary medical services in the foreseeable future should be in anticipa- 
tory care, and that one of the principal opportunities for this is in the detection and management of hypertension. ${ }^{6}$

The experts are, then, agreed; but what is happening in reality? A survey of practice records in north east Scotland last year showed that the rule of halves still applied, with only $34 \%$ of men over 20 years having a blood pressure recorded in their notes over a period of 10 years. ${ }^{7}$ Indeed, no evidence was found of any improvement in the practices over two successive five year periods. The position was similar to that shown in a study of inner London practices in 1974 by Heller and Rose, ${ }^{8}$ who also found very low standards of management of hypertension in hospitals, including teaching hospitals. ${ }^{9}$ Two more papers (pp 903, 906) show that the same lamentable approach is still apparent in London general practices, with two thirds of the adult population neglected in this way. Gross defects in management are shown, with $46 \%$ of patients in Haines's study beginning treatment after only a single reading and only three out of 84 having had urine tests. Both papers show that about a third of those who had begun to receive treatment were not continuing to have it. Particularly serious in its implications is the finding by Michael of no difference in the deficiencies between training and non-training practices.

What is to be done? It would be foolish to pretend that the task is easy. Some might claim that the management of patients with hypertension is beyond the scope of general practice altogether and should be the responsibility of hospitals. Even if it could be shown, however, that the quality of care in hospitals is better for individual patients this is largely a matter of organisation and staffing rather than clinical acumen or a personal sense of responsibility. Furthermore, the large numbers of patients needing treatment would certainly preclude a solution along these lines.

What is needed is a fundamental change in the structure of general practice. The traditional pattern is based on episodic consultations for symptomatic complaints and has no tradition of follow up. Even doctors who take pride in their achievements are often chastened by audit of their own results in chronic diseases. The primitive state of the records system inherited unmodified from the days of Lloyd George makes systematic collection of data difficult. Simple registers of hypertensive patients on card index file or on the fashionable microcomputers are a vital necessity for every practice if patients' treatment is to be maintained.

An important development which may provide the seeds of a solution is the training of nurses in the management of hypertension. In the Medical Research Council trial of treatment of mild to moderate hypertension nurses were trained to screen and treat patients in the study according to a structured protocol and achieved a high rate of compliance and satisfactory reductions in blood pressure. ${ }^{10}$ The British Hypertension Society is now running training courses for nurses. These should be supported by the Department of Health and Social Security, and nurses should be encouraged to attend by full reimbursement of expenses. Doctors must also learn the art of delegation of tasks, traditionally theirs, which they are not necessarily in a position to accomplish unaided. Despite allowances for two ancillary helpers for each principal in general practice the mean take up rate is only 1.0 so there is plenty of slack (DHSS, personal communication, 1984).

Finally, those in charge of vocational training face a serious challenge. Training practices (at least) should be reviewed by periodic audit of their management of hypertension. Some doctors may perceive this proposal as threatening, but only by facing up realistically to the problems as they are and not pretending things are better than they look will we make the really major changes that are needed. Then-in the context of hypertension-we might be more profitably employed in the next decade than in the last.

General Practitioner,

JoHN CoOpE

Bollington,

Near Macclesfield SK10 5JL

1 Veterans Administration Cooperative Study Group on Antihypertensive Agents. Effects of treatment on morbidity in hypertension. Results in patients with diastolic blood pressures averaging 115 through $129 \mathrm{~mm}$ Hg. F AMA 1967;202:1028-34.

2 Veterans Administration Cooperative Study Group on Antihypertensive Agents. Effects of treatment on morbidity in hypertension. II. Results in patients with diastolic blood pressure averaging 90 through $114 \mathrm{~mm}$ Hg. FAMA 1970;213:1143-52.

2a Management Committee. The Australian therapeutic trial in mild hypertension. Lancet 1980; :1261-7.

${ }^{3}$ Hart JT. Semicontinuous screening of a whole community for hypertension. Lancet 1970;ii:223-6.

4 Hart JT. The management of high blood pressure in general practice. f $R$ Coll Gen Pract 1975;25:160-92.

${ }^{5}$ Coope JR. Management of hypertension in general practice. In: $A B C$ of hypertension. London: British Medical Association, 1981:42-4.

6 Royal College of General Practitioners. Health and prevention in primary care. London: Royal College of General Practitioners, 1981.

7 Ritchie LD, Currie AM. Blood pressure recording by general practitioners in north-east Scotland. Br Med F 1983;286:107-9.

${ }^{8}$ Heller RF, Rose G. Current management of hypertension in general practice. $\operatorname{Br}$ Med f 1977; :1442-4.

${ }^{9}$ Heller RF, Rose G. Current management of hypertension in hospital. Br Med F 1977; i:1441-2.

10 Barnes GR. Nurse-run hypertension clinics. 7 R Coll Gen Pract 1983;33: 820-1.

\section{Natural or unnatural foods?}

Belief seems to be growing - and not just among food faddists - that in some way natural foods are to be preferred. The growing numbers of health food shops selling a wide range of natural foods is a testimony to this belief. "Natural" has (like so many words) been devalued by the advertising copywriter, and the Food Standards Committee recommended in 1966 that "natural" (as applied to food) should signify "raw, unmixed, unadulterated, and unprocessed."1

In a wider sense, however, all foods are natural, in that they are derived from plants, fungi, or animals, for the truly synthetic food of science fiction is a long way off. Nevertheless, it has been argued that the application of agricultural techniques is unnatural, that the current plant varieties and breeds of animals are the products of man's manipulation of nature, and that the closer food producers return to primitive sources and methods the more "natural"-and so the healthier-their products will be. It would be facile to dismiss this belief in the superiority of natural foods as merely a reaction to the complexities of modern living and a desire to return to the good old days. The belief in natural foods seems to rest on several tenets which need to be examined and assessed.

Firstly, natural foods are thought to be free from undesirable contamination from agrochemicals (artificial fertilisers, insecticides, pesticides, and the like). The individual consumer cannot easily assess whether or not "natural" foods are free from contaminants, but past abuses that have been given wide publicity have served to strengthen the hands of the regulating bodies. Properly used, agrochemicals do not present any real hazards, and they offer real advantages in increased yield and freedom from disease in many crops. In Britain regular surveillance of residues in foods is carried out by the Ministry of Agriculture, Fisheries and Food, and the reports of these studies are published and freely available. ${ }^{2}$ 